\title{
UNSTEADY MIXED CONVECTION NONLINEAR RADIATIVE CASSON NANOFLUID FLOW WITH CONVECTIVE BOUNDARY CONDITION, HEAT SOURCE AND INCLINED MAGNETIC FIELD EFFECTS
}

\author{
Bundit Unyong ${ }^{1}$, Mathialagan Govindaraju ${ }^{2}$, Nallappan Gunasekaran ${ }^{3}$ \\ Rajarathinam Vadivel ${ }^{1}$ \\ ${ }^{1}$ Department of Mathematics, Phuket Rajabhat University, Phuket-83000, Thailand \\ 2 Department of Mathematics, Padmavani Arts and Science College for Women, Salem, Periyar \\ University, Tamil Nadu, India \\ ${ }^{3}$ Computational Intelligence Laboratory, Toyota Technological Institute, Nagoya,468-8511, Japan \\ govimaths@gmail.com
}

Received: 16 July 2021; Accepted: 9 September 2021

\begin{abstract}
In this paper, we have studied the effect of heat source/sink on unsteady Casson nanofluid past a stretching surface with mixed convection inclined magnetic field and nonlinear thermal radiation numerically. Brownian and thermophoresis effects are studied in this nanofluid model (Buongiorno's). The governing momentum, energy, and concentration equations are PDEs that are changed into ordinary differential equations by means of suitable transformations. The fourth-order R-K method with shooting technique is adapted to yield the results of this work. The velocity, thermal, and concentration profiles are discussed with the several physical parameters. Also, skin friction, the Nusselt number, and the Sherwood number are examined with the help of the table. It is found that the enhancing value of the unsteady parameter and heat sink parameters reduce the fluid temperature, and the enhancing value of the Casson parameter and heat source parameters increase the fluid temperature. The increasing value of the inclined magnetic field parameter enhances the thermal boundary layer thickness.
\end{abstract}

MSC 2010: 74F10, 74F15, 76D27, $78 A 40$

Keywords: Casson nanofluid, inclined magnetic field, convective boundary condition, nonlinear thermal radiation

\section{Introduction}

The thermal ability of viable manufacturing processes significantly depends upon the heat transmit attributes of fluids. Their heat conductivity has determined this capability of temperature distribution of fluid. Conservative liquids have the difficulty of low transfer heat that made them unsuitable for high cooling processes. The options were to be investigated by the researchers, which could change these base fluids. Base liquid with the addition of some small size solid particles of fluid 
have very high thermal transfer fluid researched by the scientist. Finally, the researchers discovered that small size (1-100 nanometer) particles used in liquid include these particles that were nanofluids. Based on the experiments, the probability of the nano solid particles increasing the thermal transfer of the base liquid was observed. Azam et al. [1] studied the problem of Casson nanofluid flow with uniform heat generation/absorption and MHD mixed convection effects. The impact of the non-Newtonian nanofluid flow with uniform heat generation/absorption and unsteady magnetohydrodynamic effects have been analyzed by Chamkha et al. [2] . A numerical problem for Casson nanofluid flow with MHD mixed convection, uniform heat source/sink, and nonlinear thermal radiation impacts are investigated by Das et al. [3]. Recently, researchers in [4-9] have addressed Casson nanofluid flow problems in various flow fields.

The convective boundary layer non-Newtonian fluid flow model has expanded a lot of concerns due to its uses in the manufacturing, science, and engineering fields, such as polymer extrusion, geothermal, geophysical processes, heat exchangers, groundwater purification, in addition to grain storage devices, paper production, petroleum industries, aerodynamic heating, polymer and coating processing, hot rolling, etc. Some non-Newtonian characteristic materials are paint, mud, blood, polymers solutions, etc. One of the non-Newtonian category fluids is Casson fluid. It performs similarly to an elastic solid at low shear strain, and stress value is critical. Many research papers analyzed the effect of Casson fluid flow with both steady and unsteady boundary layers through the different types of plates [10-13].

The magnetic field's unsteady flow of electrically conducting liquid is utilized in several sciences and engineering fields, such as flow meters, manufacturing processes, pumps, MHD power generation, nuclear production, etc. The impact of magnetohydrodynamic with the unsteady nonlinear radiative cross nanofluid flow was analyzed by Mittal and Patel [14]. The unsteady Casson nanofluid flow past a stretching surface with MHD and radiation impact are investigated in Mukhopadhyay et al. [15]. The numerical solution of unsteady MHD radiative Casson fluid flow through a stretching surface was studied by Prashu and Nandkeolyar [16]. Naqvi et al. [17] studied the numerical solution of hydromagnetic Casson fluid flow through a vertical cylinder with entropy heat generation and the thermal radiation effect. Oyelakin et al. [18] reported the effects of dual solutions of MHD Casson fluid flow past a stretching sheet with radiation by 'Maple 2015'. There are also valuable articles in this area that are presented in Azam et al. [19], Khan et al. [20], Azam et al. [21]

To the best of author's knowledge, up to now, no theoretical results are given for the effects of heat source/sink and mixed convection MHD Casson nanofluid flow with nonlinear thermal radiation and convective boundary condition numerically. In this article, studied by the effect of velocity, temperature, and concentration profiles are discussed with various pertinent physical parameters. Skin friction, the Nussult number, and the Sherwood number are examined with the help of a table. Finally, our results are verified and compared with previously published work. 


\section{Formulation of the problem}

Here, nonlinear thermal radiation and unsteady two dimensional laminar Casson nanofluid through a nonlinear stretching surface with stretching velocity $u(x, t)=$ $=c x /(1-\alpha t)$. Where $c>0, \alpha \geq 0$ are constants and ' $t^{\prime}$ is time, and inclined magnetic field of strength $B_{0}$ is considered (Fig. 1). It is assumed that the temperature $T_{w}$ and concentration at the surface $C_{w}$ are constant and $T_{\infty}$ and $C_{\infty}$ are also considered as they are the free stream team temperature and concentration, respectively. The basic governing equation of momentum, continuity, energy and concentration of unsteady Casson nanofluid flow has been given by $[3,11,18]$

$$
\begin{gathered}
\frac{\partial u}{\partial x}+\frac{\partial v}{\partial y}=0 \\
\frac{\partial u}{\partial t}+u \frac{\partial u}{\partial x}+v \frac{\partial u}{\partial y}=v\left(1+\frac{1}{\beta}\right) \frac{\partial^{2} u}{\partial y^{2}}+g \beta_{T}\left(T-T_{\infty}\right)+g \beta_{C}\left(C-C_{\infty}\right) \\
-\frac{\sigma B_{0}^{2}}{\rho} u \sin ^{2} \gamma \\
\frac{\partial T}{\partial t}+u \frac{\partial T}{\partial x}+v \frac{\partial T}{\partial y}=\alpha \frac{\partial^{2} T}{\partial y^{2}}-\frac{1}{(\rho C)_{f}} \frac{\partial q_{r}}{\partial y}+\frac{(\rho C)_{p}}{(\rho C)_{f}}\left[D_{B} \frac{\partial C}{\partial y} \frac{\partial T}{\partial y}+\frac{D_{T}}{T_{\infty}}\left(\frac{\partial T}{\partial y}\right)^{2}\right] \\
+\frac{Q_{0}}{(\rho C)_{f}}\left(T-T_{\infty}\right), \\
\frac{\partial C}{\partial t}+u \frac{\partial C}{\partial x}+v \frac{\partial C}{\partial y}=D_{B}\left(\frac{\partial^{2} C}{\partial y^{2}}\right)+\frac{D_{T}}{T_{\infty}}\left(\frac{\partial^{2} T}{\partial y^{2}}\right)
\end{gathered}
$$

with the boundary conditions

$$
\begin{aligned}
& u=u(x, t), v=0,-k \frac{\partial T}{\partial y}=h\left(T_{w}-T\right), T=T_{w}, C=C_{w} \text { at } y=0 \\
& u \rightarrow 0, \quad v \rightarrow 0, T \rightarrow T_{\infty}, C \rightarrow C_{\infty} \text { as } y \rightarrow \infty,
\end{aligned}
$$

where $x$ and $y$ are the coordinate axis and $u$ and $v$ are the velocity component respectively. Also, $\sigma, \beta, v, g, \beta_{T},(\rho C)_{p}, D_{T}, D_{B},(\rho C)_{f}, \beta_{C}$ and $\alpha$ are the electrical conductivity of the fluid, non-Newtonian Casson parameter, kinematic viscosity, gravity, coefficient of thermal expansion, effective heat capacity of the nanoparticle, thermophoresis diffusion coefficient, Brownian diffusion coefficient, effective heat capacity of the fluid, coefficient of expansion with concentration and the thermal diffusity respectively. Temperature of liquid is $T$, concentration of liquid is $C, Q_{0}$ is the heat source/sink coefficient, and radiative heat flux is $q_{r}$. 


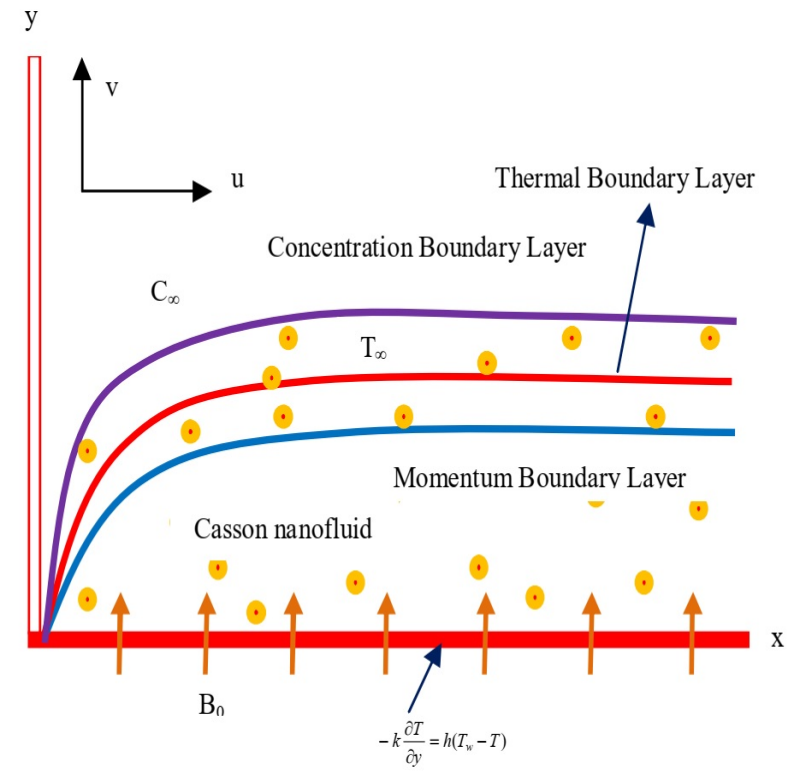

Fig. 1. Geometry of the problem

The following radiative heat flux is $[3,11]$ (Roseland approximation)

$$
q_{r}=-\frac{4 \sigma^{*}}{3 k^{*}} \frac{\partial T^{4}}{\partial y}
$$

The nonlinear structure of thermal radiation is considered. Equation (3) can be written as (see $[3,11])$

$$
\begin{aligned}
\frac{\partial T}{\partial t}+u \frac{\partial T}{\partial x}+v \frac{\partial T}{\partial y}=\alpha \frac{\partial^{2} T}{\partial y^{2}}+ & \frac{16 \sigma^{*} T_{\infty}^{3}}{3 k^{*}(\rho C)_{f}} \frac{\partial^{2} T}{\partial y^{2}}+\frac{(\rho C)_{p}}{(\rho C)_{f}}\left[D_{B} \frac{\partial C}{\partial y} \frac{\partial T}{\partial y}+\frac{D_{T}}{T_{\infty}}\left(\frac{\partial T}{\partial y}\right)^{2}\right] \\
& +\frac{Q_{0}}{(\rho C)_{f}}\left(T-T_{\infty}\right) .
\end{aligned}
$$

The stream function $(\psi)$, which is non-dimensional form and the similarity variable are as follows:

$$
\psi=\sqrt{\frac{a v}{(1-\alpha t)}} x f(\eta), \eta=y \sqrt{\frac{a}{v(1-\alpha t)}}, \theta(\eta)=\frac{T-T_{\infty}}{T_{w}-T_{\infty}}, \phi(\eta)=\frac{C-C_{\infty}}{C_{w}-C_{\infty}} .
$$

The parameter of the temperature ratio is $\theta_{w}=\frac{T_{w}}{T_{\infty}}>1$, and we also obtained $T=T_{\infty}\left(1+\left(\theta_{w}-1\right) \theta\right)$. Using (8) in the (2), (7) and (4), we obtained the following ODEs which are

$$
\left(1+\frac{1}{\beta}\right) f^{\prime \prime \prime}+f f^{\prime \prime}-A\left(\frac{1}{2} \eta f^{\prime \prime}+f^{\prime}\right)-f^{\prime 2}+R i_{T}(\theta-N \phi)-M f^{\prime} \sin ^{2} \gamma=0,
$$




$$
\begin{gathered}
\left(1+\frac{4}{3 R}\left(1+\left(\theta_{w}-1\right) \theta\right)^{3}\right) \theta^{\prime \prime}-A \operatorname{Pr}\left(2 \theta+\frac{\eta}{2} \theta^{\prime}\right)-2 \operatorname{Pr}^{\prime} \theta+\operatorname{Pr} f \theta^{\prime}+N b \operatorname{Pr} \phi^{\prime} \theta^{\prime} \\
+N t \operatorname{Pr} \theta^{\prime 2}+\frac{4}{R}\left(\theta_{w}-1\right)\left(1+\left(\theta_{w}-1\right) \theta\right)^{2} \theta^{\prime 2}+\delta \theta=0 \\
\phi^{\prime \prime}=S c\left(A\left(2 \phi+\frac{\eta}{2} \phi^{\prime}\right)+2 f^{\prime} \phi-f \phi^{\prime}\right)-\frac{N t}{N b} \theta^{\prime \prime}
\end{gathered}
$$

The corresponding surface conditions are

$$
\begin{aligned}
& f(0)=0, f^{\prime}(0)=1, \theta^{\prime}(0)=-B i(1-\theta(0)), \phi(0)=1 \\
& f^{\prime}(0) \rightarrow 0, \theta(\eta) \rightarrow 0 \phi(\eta) \rightarrow 0 \text { as } \eta \rightarrow \infty .
\end{aligned}
$$

Where $N t, B i, N b, A, R, S c, \operatorname{Pr}, \delta$ and $M$ are the Thermophoresis parameter, Biot number, Brownian motion parameter, unsteady parameter, nonlinear thermal radiation, Schmidt number, Prandtl number, heat source/sink parameter, and magnetic parameter respectively. These parameters are defined as

$$
\begin{aligned}
& S c\left(=\frac{v}{D_{B}}\right), N t\left(=\frac{(\rho C)_{p} D_{T}\left(T_{w}-T_{\infty}\right)}{v(\rho C)_{f} T_{\infty}}\right), N b\left(=\frac{(\rho C)_{p} D_{B}\left(C_{w}-C_{\infty}\right)}{v(\rho C)_{f}}\right), A\left(=\frac{c}{a}\right), \\
& B i\left(=\frac{h_{f}}{k} x \operatorname{Re}^{\frac{-1}{2}}\right), R\left(=\frac{4 \sigma^{*} T_{\infty}^{3}}{k k^{*}}\right), \operatorname{Pr}\left(=\frac{v}{\alpha}\right), \delta\left(=\frac{Q_{0}}{a(\rho C)_{f}}\right), M\left(=\frac{\sigma B_{0}^{2}}{\rho a}\right) .
\end{aligned}
$$

The physical quantities from an engineering point of view, in this study the Skin friction, Nusselt number and Sherwood number are defined as [18]

$$
C_{f x}=\frac{\tau_{w}}{\rho U_{w}{ }^{2}}, \quad N u_{x}=\frac{x q_{w}}{k\left(T_{w}-T_{\infty}\right)}, \quad S h_{x}=\frac{x q_{m}}{D_{B}\left(C_{w}-C_{\infty}\right)} .
$$

That $\tau_{w}$ the wall shear stress, $q_{w}$ the wall heat flux and $q_{m}$ the mass flux are respectively equal to:

$\tau_{w}=\left(1+\frac{1}{\beta}\right)\left(\frac{\partial u}{\partial y}\right)_{y=0}, q_{w}=\left(-\left(k+\frac{16 \sigma^{*} T_{\infty}{ }^{3}}{3 k^{*}}\right)\left(\frac{\partial T}{\partial y}\right)\right)_{y=0}, q_{m}=-D_{B}\left(\frac{\partial T}{\partial y}\right)_{y=0}$.

In non-dimensional form, we get

$$
\begin{aligned}
& C_{f x} R e_{x}^{\frac{-1}{2}}=\left(1+\frac{1}{\beta}\right) f^{\prime \prime}(0), N u_{x} R e_{x}^{\frac{-1}{2}}=-\left(1+\frac{4}{3 R}\left(1+\left(\theta_{w}-1\right) \theta\right)^{3}\right) \theta^{\prime}(0), \\
& S h_{x} R e_{x}^{\frac{-1}{2}}=-\phi^{\prime}(0) .
\end{aligned}
$$

\section{Numerical method for solution}

The non-linear differential Eqs. (9) and (10) along with the boundary condition (12) form a two-point boundary value problem and are solved using a shooting technique together with a fourth-order Runge-Kutta integration scheme by converting 
the non-linear differential equations into an initial value problem. We then have to solve the system of first order ordinary differential equations given by

$f^{\prime}=q ; \quad q^{\prime}=p ;$
$p^{\prime}=\frac{A\left(\frac{1}{2} \eta q^{\prime}+q\right)-f q^{\prime}+q^{2}-R i_{T}(\theta-N \phi)+M q \sin ^{2} \gamma}{\left(1+\frac{1}{\beta}\right)}$,

$\theta^{\prime}=y$

$y^{\prime}=\frac{\operatorname{Pr}\left(A\left(2 \theta+\frac{\eta}{2} y\right)+2 q \theta-f y-N b z y-N t y^{2}\right)}{\left(1+\frac{4}{3 R}\left(1+\left(\theta_{w}-1\right) \theta\right)^{3}\right)}+\frac{4}{R}\left(\theta_{w}-1\right)\left(1+\left(\theta_{w}-1\right) \theta\right)^{2} y^{2}+\delta \theta,(16)$

$\phi^{\prime}=z ; \quad z^{\prime}=S c\left(A\left(2 \phi+\frac{\eta}{2} z\right)+2 q \phi-f z\right)-\frac{N t}{N b} y^{\prime}$,

with the boundary conditions

$f(0)=0, f^{\prime}(0)=1, \theta^{\prime}(0)=-B i(1-\theta(0)), \phi(0)=1$.

Now we solve (15)-(17) with (18), need the values for $p(0)$ i.e. $f^{\prime \prime}(0), y(0)$ i.e. $\theta^{\prime}(0)$ and $z(0)$ i.e. $\phi^{\prime}(0)$ but no such values are given. The solution is obtained with the help of the shooting technique among the fourth order R-K method before obtaining the initial guess values for $f^{\prime \prime}(0), \theta^{\prime}(0)$ and $\phi^{\prime}(0)$ are chosen. After that, we evaluate the computed values of $f^{\prime}(\eta), \theta(\eta)$ and $\phi(\eta)$ at $\eta_{\infty}$ with the given boundary conditions $f^{\prime}\left(\eta_{\infty}\right)=0, \theta\left(\eta_{\infty}\right)=0$ and $\phi\left(\eta_{\infty}\right)=0$, and adjust the values of $f^{\prime \prime}(0), \theta^{\prime}(0)$ and $\phi^{\prime}(0)$ using shooting technique to give better approximation for the solution. The process is repeated until we get the results correct up to the desired accuracy of $10^{-9}$ level, which fulfils the convergence criterion.

\section{Discussion of results}

The various pertinent parameters on the fluid flow effects are analyzed in this section. Here, the parameter's values $(A=0.2, P r=1, R i T=0.5, N=0.5, N b=0.5$, $N t=0.5, M=1, \theta_{w}=1.1, R=0.3, B i=1, \gamma=45^{0}, \beta=0.5, S c=1$ and $\left.\delta=0.2\right)$ are fixed throughout the study. The impact of pertinent flow parameters on the numerical solutions, such as unsteady parameter $(A)$, inclined angle parameter $(\gamma)$, Casson parameter $(\beta)$ and magnetic parameter $(M)$ on velocity and thermal profiles are investigated, in addition to the heat source/sink parameter $(\delta)$ and nonlinear thermal radiation parameter $(R)$ on thermal and concentration profiles that are also analyzed. The various values of the aforementioned parameters on the Skin friction, coefficient of heat transfer and coefficient of mass transfer are summarized in the tabular form (Table 1). Also, confirmation of our numerical performance is tested by Sulochana et al. [22] and Usman et al. [23] (Table 2).

To examine the influences of the Casson parameter on fluid velocity, temperature, and concentration profiles are represented in Figures 2, 3, and 4, respectively. From 
these figures, it is clear that the velocity profile is diminishing, and the momentum surface layer thickness is reduced when the Casson parameter enhances. The temperature of the fluid and nanoparticle concentration profiles are improved when the Casson parameter is increased. The presence of the Casson parameter controls the fluid moment because it creates fluid friction. So, that is the reason fluid temperature and concentration boundary layers are enhanced.

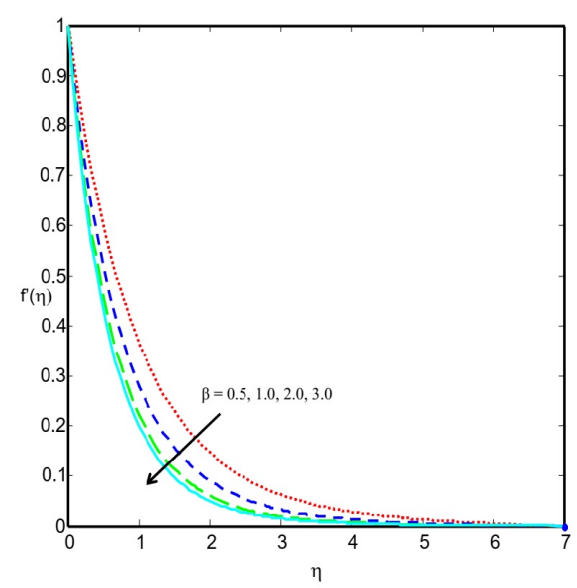

Fig. 2. Variations of $f^{\prime}(\eta)$ with $\beta$

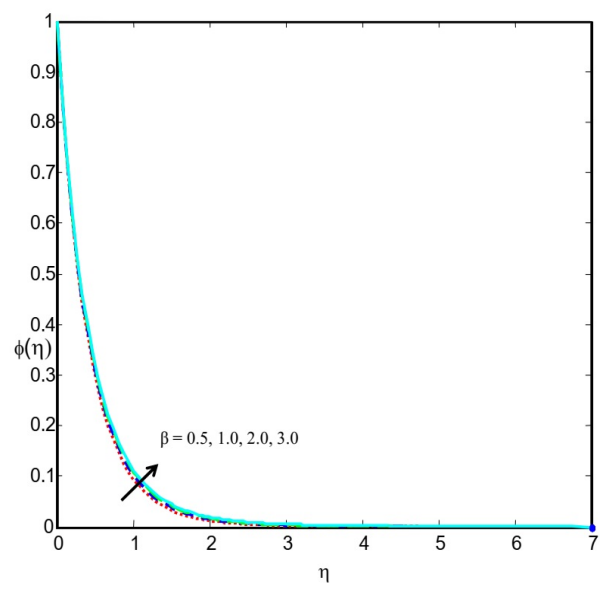

Fig. 4. Variations of $\phi(\eta)$ with $\beta$

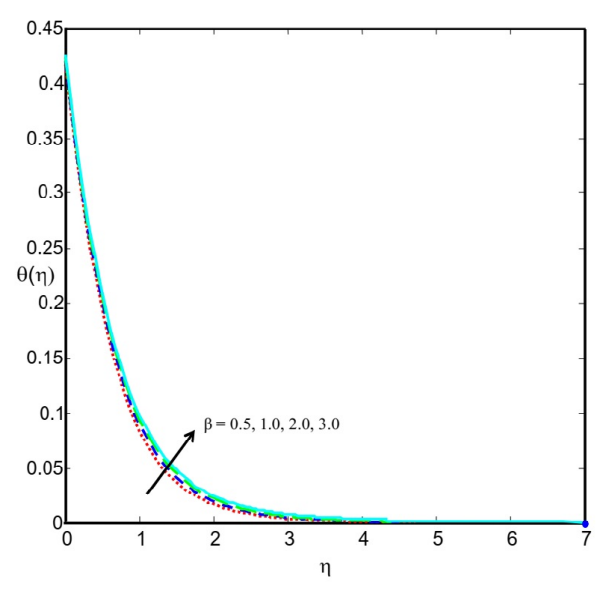

Fig. 3. Variations of $\theta(\eta)$ with $\beta$

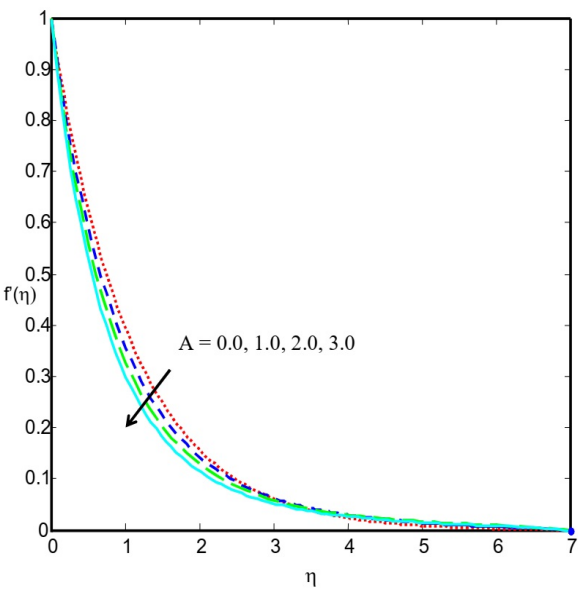

Fig. 5. Variations of $f^{\prime}(\eta)$ with $A$

The results of unsteady parameters on velocity, thermal, and concentration profiles are shown in Figures 5, 6, and 7. The concentration, thermal, and velocity boundary layers thicknesses reduce the enhancing value of the unsteady parameter. Physically, less heat is transferred from the sheet to the fluid when the unsteadiness parameter increases. For this reason, the temperature profile decreases. Since the fluid flow is caused solely by the stretching sheet, and the sheet surface temperature is higher 


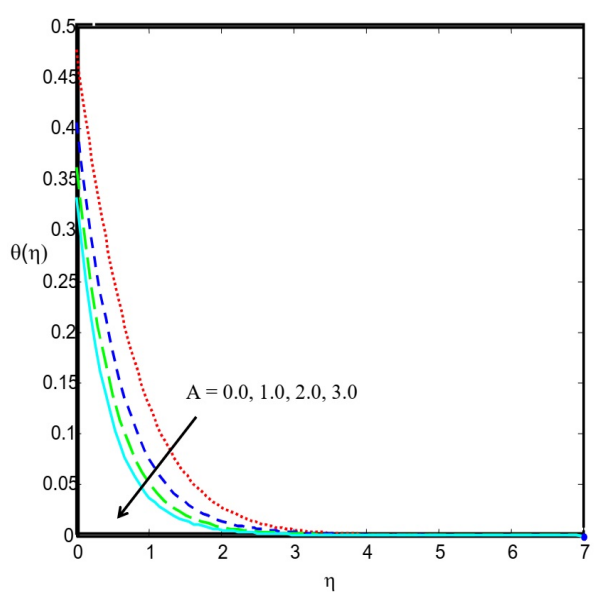

Fig. 6. Variations of $\theta(\eta)$ with $A$

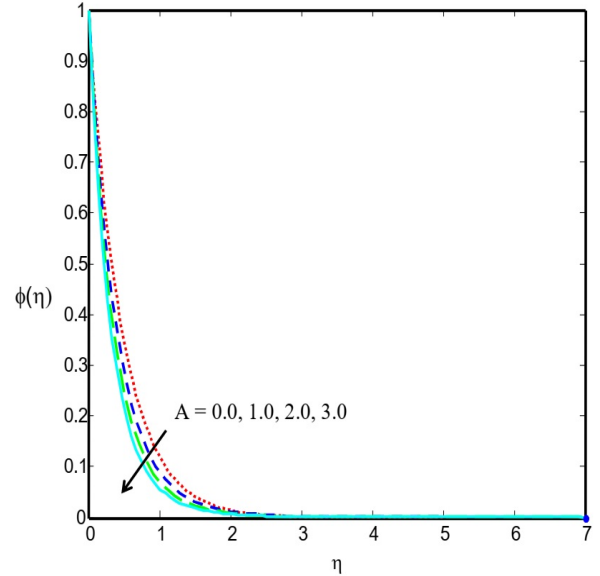

Fig. 7. Variations of $\phi(\eta)$ with $A$

than the free-stream temperature, the fluid velocity and temperature decrease as the unsteady parameter increases. It is important to note that the rate of cooling is much faster for higher values of the unsteadiness parameter. When unsteady parameter values are increased in the system, the boundary layer thicknesses are reduced, and this inhibits the development of transition from laminar to turbulent flow.

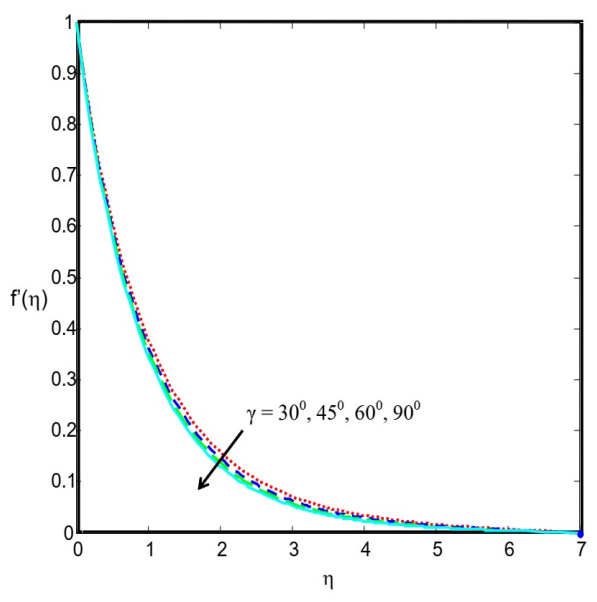

Fig. 8. Variations of $f^{\prime}(\eta)$ with $\gamma$

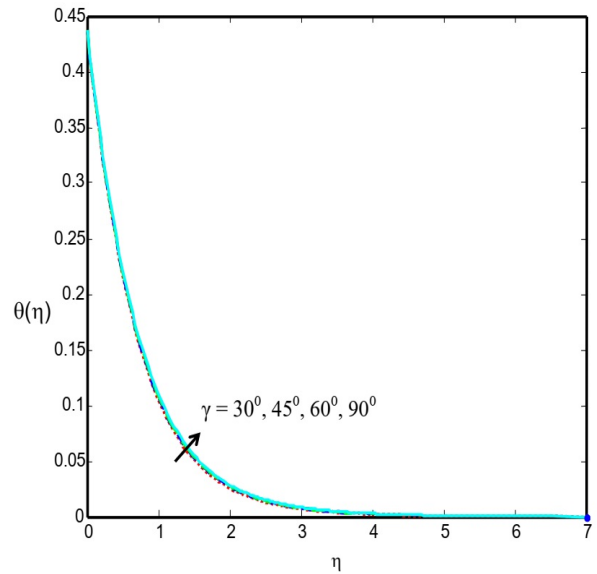

Fig. 9. Variations of $\theta(\eta)$ with $\gamma$

The impact of an inclined angle and magnetic parameters on the velocity of the fluid, the temperature of the fluid, and nanofluid concentration profiles are depicted in Figures 8, 9, 10, 11, 12, and 13, respectively. Enhancing the value of the inclined magnetic field slows down the fluid motion and temperature of the fluid, and the concentration of the nanofluids are increased. This is due to the fact that the increasing values of the inclined magnetic field create the Lorentz force, which is related to the drag force; therefore, it slows down the liquid motion and improves the heat transfer 


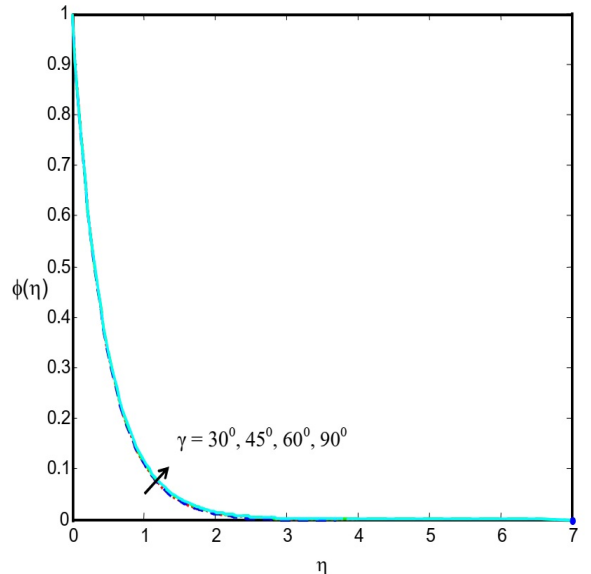

Fig. 10. Variations of $\phi(\eta)$ with $\gamma$

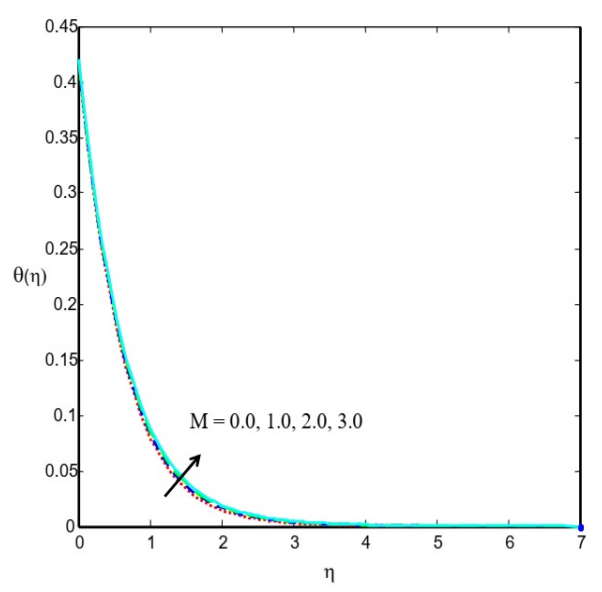

Fig. 12. Variations of $\theta(\eta)$ with $M$

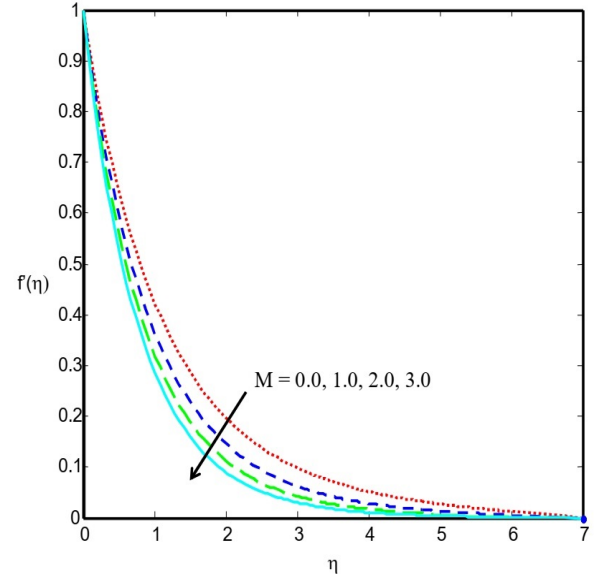

Fig. 11. Variations of $f^{\prime}(\eta)$ with $M$

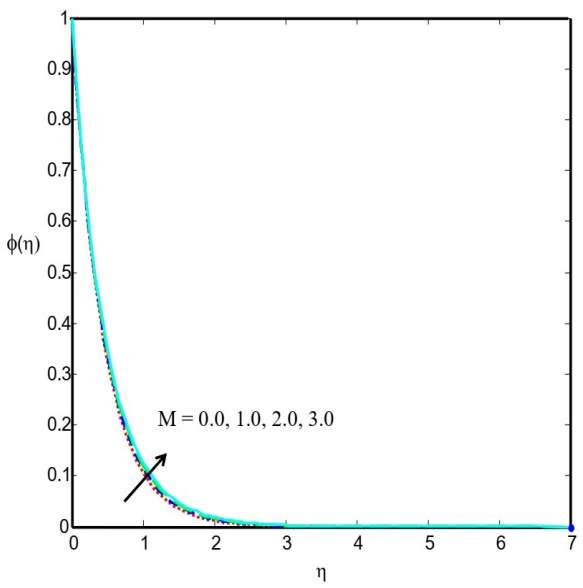

Fig. 13. Variations of $\phi(\eta)$ with $M$

and concentration process. The presence of an inclined magnetic field enhances the concentration and thermal boundary layers and diminishing the momentum boundary layer.

From Figure 14, the influence of heat source/sink upon the thermal profile for Casson nanofluid can be noticed. It is perceived that the heat surface layer thickness slightly increases in the case of heat source, which is the value of $\delta>0$ and releases the thermal energy to the flow. The thermal boundary layer thickness reduced in the case of heat sink, which is the value of $\delta<0$. Physically, in this case, heat energy is observed. Figure 15 portrays the role of thermal radiation on the temperature plot. A large value of $R$ is observed to boost the temperature plot. This implies an enhancement in the thermal layer thickness. Physically, the thermal radiation helps to boost the thermal situation of the liquid environment. Hence, increasing $R$ helps to 


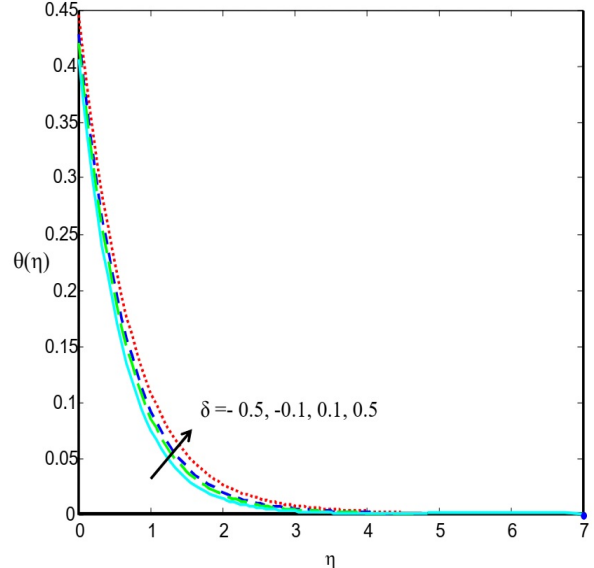

Fig. 14. Variations of $\theta(\eta)$ with $\delta$

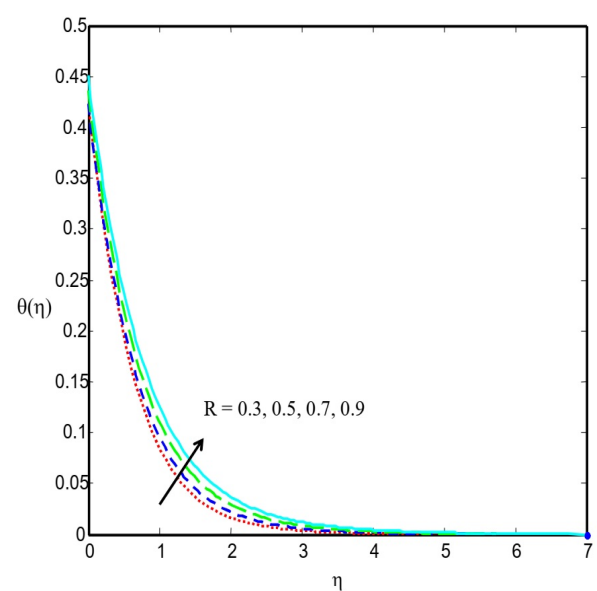

Fig. 15. Variations of $\theta(\eta)$ with $R$

Table 1. Deviation of Skin friction coefficient, heat transfer rate and mass transfer coefficient

\begin{tabular}{lllllllllllll}
\hline$A$ & $M$ & $\gamma$ & $\beta$ & $P r$ & $R$ & $N b$ & $N t$ & $B i$ & $\delta$ & $C_{f x} R e_{x}^{-1 / 2}$ & $N u_{x} R e_{x}^{-1 / 2}$ & $S h_{x} R e_{x}^{-1 / 2}$ \\
\hline 0.2 & 1 & $45^{0}$ & 0.5 & 1.0 & 0.3 & 0.5 & 0.5 & 1.0 & 0.2 & & & \\
0.0 & & & & & & & & & & 0.9281125 & 0.5231267 & 2.0707790 \\
1.0 & & & & & & & & & & 1.0748654 & 0.5945184 & 2.5212629 \\
2.0 & & & & & & & & & & 1.2041731 & 0.6374435 & 2.8937544 \\
3.0 & & & & & & & & & & 1.3203179 & 0.6675840 & 3.2174464 \\
& 0.0 & & & & & & & & & 0.8989686 & 0.5855297 & 2.4579342 \\
& 1.0 & & & & & & & & & 1.0470854 & 0.5834064 & 2.4387045 \\
& 2.0 & & & & & & & & & 1.1730465 & 0.5816593 & 2.4229163 \\
& 3.0 & & & & & & & & & 1.2846312 & 0.5801567 & 2.4093685 \\
\hline
\end{tabular}

boost the heat on the liquid and hereby lead to enhancement in the temperature of the liquid.

The numerically computed values of mass and heat transfer coefficients and friction factors are reported in Table 2. It is scrutinized from the Table 2 Casson nanofluid friction improves with an unsteady parameter and a magnetic parameter. Heat transfer rate improves with unsteady parameter, and is reduced with the magnetic parameter. The Sherwood number improves by increasing the value of the unsteady parameter, and is reduced with magnetic parameter.

Table 2. Comparison results of Skin friction coefficient for unsteadiness parameter A

\begin{tabular}{llll}
\hline A & Present results & Sulochana et al. [22] & Usman et al. [23] \\
\hline 0.8 & -1.261133 & -1.261479 & -1.261512 \\
1.2 & -1.377734 & -1.377850 & -1.378052 \\
\hline
\end{tabular}




\section{Conclusion}

In this article, the mixed convection Lorentz force effect on unsteady Casson nanofluid flow through a stretching surface with heat source/sink, nonlinear thermal radiation and convective heat transfer has been studied. The important solutions are listed as follows:

- The nanofluid velocity improves with the presence of declining value of unsteady, Casson and inclined magnetic field.

- The nanofluid thermal field was enhanced with the higher values of the Casson, inclined magnetic field, thermal radiation, and heat source parameters, while it declines with improving the value of the unsteady parameter and heat sink parameter.

- The nanofluid concentration boundary layer thickness is developing with increasing value of the Casson parameter and inclined magnetic field, during its decline with the increasing value of the unsteady parameter.

\section{References}

[1] Azam, M., Shakoor, A., Rasool, H., \& Khan, M. (2019). Numerical simulation for solar energy aspects on unsteady convective flow of mhd cross nanofluid: A revised approach. International Journal of Heat and Mass Transfer, 131, 495-505.

[2] Chamkha, A., Aly, A., \& Mansour, M. (2010). Similarity solution for unsteady heat and mass transfer from a stretching surface embedded in a porous medium with suction/injection and chemical reaction effects. Chemical Engineering Communications, 197(6), 846-858.

[3] Das, M., Mahato, R., \& Nandkeolyar, R. (2015). Newtonian heating effect on unsteady hydromagnetic casson fluid flow past a flat plate with heat and mass transfer. Alexandria Engineering Journal, 54(4), 871-879.

[4] Eid, M.R., \& Mahny, K.L. (2017). Unsteady mhd heat and mass transfer of a non-newtonian nanofluid flow of a two-phase model over a permeable stretching wall with heat generation/absorption. Advanced Powder Technology, 28(11), 3063-3073.

[5] Gbadeyan, J., Titiloye, E., \& Adeosun, A. (2020). Effect of variable thermal conductivity and viscosity on casson nanofluid flow with convective heating and velocity slip. Heliyon, 6(1), e03076.

[6] Ghadikolaei, S., Hosseinzadeh, K., Ganji, D., \& Jafari, B. (2018). Nonlinear thermal radiation effect on magneto casson nanofluid flow with joule heating effect over an inclined porous stretching sheet. Case Studies in Thermal Engineering, 12, 176-187.

[7] Hakeem, A.A., Renuka, P., Ganesh, N.V., Kalaivanan, R., \& Ganga, B. (2016). Influence of inclined lorentz forces on boundary layer flow of casson fluid over an impermeable stretching sheet with heat transfer. Journal of Magnetism and Magnetic Materials, 401, 354-361.

[8] Haldar, S., Mukhopadhyay, S., \& Layek, G. (2019). Flow and heat transfer of casson fluid over an exponentially shrinking permeable sheet in presence of exponentially moving free stream with convective boundary condition. Mechanics of Advanced Materials and Structures, 26(17), 1498-1504.

[9] Hamid, M., Usman, M., Khan, Z., Ahmad, R., \& Wang, W. (2019). Dual solutions and stability analysis of flow and heat transfer of casson fluid over a stretching sheet. Physics Letters A, $383(20), 2400-2408$. 
[10] Ibrahim, S., Lorenzini, G., Kumar, P.V., \& Raju, C. (2017). Influence of chemical reaction and heat source on dissipative mhd mixed convection flow of a casson nanofluid over a nonlinear permeable stretching sheet. International Journal of Heat and Mass Transfer, 111, 346-355.

[11] Mabood, F., \& Das, K. (2019). Outlining the impact of melting on mhd casson fluid flow past a stretching sheet in a porous medium with radiation. Heliyon, 5(2), e01216.

[12] Mackolil, J., \& Mahanthesh, B. (2019). Exact and statistical computations of radiated flow of nano and casson fluids under heat and mass flux conditions. Journal of Computational Design and Engineering, 6(4), 593-605.

[13] Mahmood, A., Jamshed, W., \& Aziz, A. (2018). Entropy and heat transfer analysis using cattaneochristov heat flux model for a boundary layer flow of casson nanofluid. Results in Physics, 10, 640-649.

[14] Mittal, A.S., \& Patel, H.R. (2020). Influence of thermophoresis and brownian motion on mixed convection two dimensional MHD Casson fluid flow with non-linear radiation and heat generation. Physica A: Statistical Mechanics and its Applications, 537, 122710.

[15] Mukhopadhyay, S., De, P.R., Bhattacharyya, K., \& Layek, G. (2013). Casson fluid flow over an unsteady stretching surface. Ain Shams Engineering Journal, 4(4), 933-938.

[16] Prashu, \& Nandkeolyar, R. (2018). A numerical treatment of unsteady three-dimensional hydromagnetic flow of a casson fluid with hall and radiation effects. Results in Physics, 11, 966-974.

[17] Naqvi, S.M.R.S., Muhammad, T., \& Asma, M. (2020). Hydromagnetic flow of casson nanofluid over a porous stretching cylinder with newtonian heat and mass conditions. Physica A: Statistical Mechanics and its Applications, 550, 123988.

[18] Oyelakin, I.S., Mondal, S., \& Sibanda, P. (2016). Unsteady casson nanofluid flow over a stretching sheet with thermal radiation, convective and slip boundary conditions. Alexandria Engineering Journal, 55(2), 1025-1035 .

[19] Azam, M., Khan, M., \& Alshomrani, A.S. (2017). Unsteady radiative stagnation point flow of MHD Carreau nanofluid over expanding/contracting cylinder. Int. J. Mech. Sci., 130(2017), 64-73.

[20] Khan, M., \& Azam, M. (2017). Unsteady heat and mass transfer mechanisms in MHD Carreau nanofluid flow. J. Mol. Liq., 225, 554-562.

[21] Azam, M., Xu, T., \& Khan, M. (2020). Numerical simulation for variable thermal properties and heat source/sink in flow of Cross nanofluid over a moving cylinder. Int. Commun. Heat Mass Transf., 118, 104832.

[22] Sulochana, C., Ashwinkumar, G., \& Sandeep, N. (2018). Effect of frictional heating on mixed convection flow of chemically reacting radiative casson nanofluid over an inclined porous plate. Alexandria Engineering Journal, 57(4), 2573-2584.

[23] Usman, M., Soomro, F.A., Haq, R.U., Wang, W., \& Defterli, O. (2018). Thermal and velocity slip effects on casson nanofluid flow over an inclined permeable stretching cylinder via collocation method. International Journal of Heat and Mass Transfer, 122, 1255-1263. 